\section{¿Qué es el rodeo? Desensamblando las piezas de un ritual nacionalista*}

\section{What is rodeo? \\ Disassembling the pieces of a nationalist ritual}

\author{
Juan Carlos Skewes
}

\section{Resumen}

El rodeo en tanto ícono de la nacionalidad se analiza a partir de la doble perspectiva de la ontología y economía política revelándose las contradicciones que su despliegue entraña en la

\footnotetext{
Este artículo es fruto de los resultados del proyecto Fondecyt F1140598: Antropología del Bosque. Se agradece a Nelson Soto Santibáñez, quien me invitara a sistematizar esta experiencia. Agradezco, además, a los pares evaluadores y a la dirección de la revista por los comentarios que permitieron corregir la version original del texto.

** Universidad Alberto Hurtado, Departamento de Antropología. Almirante Barroso 10, Santiago. jskewes@uahurtado.cl
}

constitución clasista de la sociedad chilena. La apropiación de prácticas populares asociadas al arreo de animales y su incorporación al repertorio simbólico ritual nacional además de constituir una forma de legitimación de la hegemonía hacendal importa la imposición de un modelo ontológico que termina por separar y someter no solo a las personas entre sí sino también disociar los vínculos que unen a seres humanos y animales y al paisaje del que son parte constitutiva. En efecto, el proclamado deporte nacional reconoce raíces en la vida cordillerana de la que son actores principales los arrieros y es, justamente, la apropiación de su trabajo y de sus medios de reproducción y de vida lo que logra consagrarse a través del ritual como el asiento simbólico de las clases hegemónicas. Se concluye que en el contexto de un nacionalismo creciente, estas instituciones y prácticas merecen una revisión crítica que, haciéndose cargo del carácter opresivo que ellas tienen, reconozcan su lugar en la configuración de las identidades locales y regionales.

Palabras clave: Ecología política, antropología del deporte, rito, nacionalismo

\begin{abstract}
The double perspective of ontology and political economy allows analyzing rodeo as an icon of nationality revealing the contradictions that its deployment entails in the class constitution of Chilean society. The appropriation of popular practices associated with animal herding and their incorporation into the national ritual symbolic repertoire, while a means of legitimization of landowners' hegemony, entails the imposition of an ontological model that
\end{abstract}


ends up separating and subjecting not only people from each other, but also dissociating the links that unite humans and animals and the landscape of which they are a constituent part. In effect, the proclaimed national sport traces its roots in the cordilleran life of which the arrieros (muleteers) are main actors, and it is, precisely, the appropriation of their work and means of reproduction and life what allows to consecrate the ritual as the symbolic seat of hegemonic classes. In the context of growing nationalism, these institutions and practices deserve a critical review that, identifying the oppressive nature that they have, recognizes their place in the configuration of local and regional identities.

Key words: Political ecology, anthropology of sports, ritual, nationalism.

\section{Introducción}

En un artículo periodístico, importantes intelectuales chilenos, de orientaciones ideológicas diversas, coincidían en lo que el titular de la nota enunciaba: "Historiadores ponen la lápida al rodeo: ya no responde a la cultura del Chile del presente aseguran". Se trataba de Gabriel Salazar, Sergio Villalobos, Cristian Medina y William San Martín, y los calificativos que se empleaban para dar cuenta de este deporte iban desde "una pobre manifestación de cultura popular" hasta "no es una costumbre popular mestiza propia del pueblo chileno" (Fajardo 2017). No obstante, su práctica sigue al fútbol en cuanto a popularidad y se desarrolla desde Arica hasta la provincia Antártica.

Distinta es la perspectiva que la elite mantiene respecto del rodeo. La presencia del Presidente de la República en la celebración de los setenta años del Champion de Chile en la medialuna de Rancagua, en abril de 2018, deja en claro el papel que el rodeo está llamado a cumplir en la sociedad chilena. "Es parte de nuestra riqueza, es parte de nuestra identidad, y la queremos conservar, la queremos fortalecer", señala el Mandatario (El Desconcierto 09.04.2018). No en vano, el 10 de enero de 1962, bajo el gobierno conservador de la época, se le declara por oficio como un deporte nacional.

En una era en que los rebrotes chauvinistas cobran dimensiones amenazantes para los derechos humanos, de las mujeres, de las minorías y de los animales, es relevante preguntarse acerca del papel del rodeo como expresión del nacionalismo criollo. En este artículo se plantea que la celebración de este deporte encubre los mecanismos de desposesión a partir de los que se constituye el poder hacendal; al mismo tiempo que provee los medios para su legitimación.

La práctica del rodeo, como una faena de montaña, practicada por los arrieros, constituye una de las múltiples expresiones autónomas de recreación popular (Purcell 2000). Sin embargo, en el marco de la hacienda, se le instrumentaliza con el fin de constituirle en un espectáculo que sirve los propósitos de la dominación. La espectacularización del rodeo da cuenta, a su vez, de la imposición de un proyecto histórico moderno, de carácter individualista y mercantil, a modos de vidaforjadoscolectivamente. El desdén que la intelectualidad pueda manifestar acerca del rodeo aparece, desde esta perspectiva, más como una debilidad del observador que como una del fenómeno observado.

El rodeo es parte de los ritos de hacienda y durante el siglo XIX y anteriores se encontraba 
articulado con el sistema de dominación rural que caracterizó a esa institución en Chile (Bauer 1994; Bengoa 1988, 1990; Kay 1980). No obstante, ya en el siglo XIX y en las primeras décadas del siguiente, la actividad comienza a formalizarse y a profesionalizarse, definiéndosela como un deporte en 1960 (Montory-Gajardo 2018; Muller 2004). ${ }^{1}$ Este tránsito coincide con la espectacularización del rodeo y con su progresivo divorcio de la hacienda, la cual, a su vez, pierde el papel estructurante que había jugado en el pasado (Bengoa 1990). En esta etapa, el rodeo se reinventa como un deporte y su papel se afinca, hasta nuestros días, como un ícono del ideario nacionalista. ${ }^{2}$

El deporte masivo, en general y especialmente a partir de fines del siglo veinte, asume funciones supletorias en relación a la configuración de identidades nacionales efectistas pero carentes de sustento como resultado de la incapacidad de los Estados de generar a través de la modernización proyectos comunes e inclusivos para su población (Alabarces 1998). Y el deporte del rodeo no parece ser ajeno a ello: a través suyo se inventa una comunidad que no existe. En los albores de lo que es la actual antropología del deporte, los trabajos pioneros de Roberto Da Matta (Da Matta et al. 1982), Ano Vogel (Da Matta et al. 1982), Eduardo Archetti (1999) y Pablo Alabarces $(2015,2006)$, prestaron especial atención a esta relación entre identidad nacional y deporte, particularmente el fútbol. ${ }^{3}$

Montory-Gajardo (2016) sugiere que el rodeo se inicia como deporte el año 1860.

2 El Reglamento para Juzgar las "Corridas de Vacas" se dicta en octubre de 1929 (ver Memoria Chilena, http://www. memoriachilena.gob.cl/archivos2/pdfs/MC0053532.pdf).

3 Tema que, en Chile, fuera asumido por Andrés Recasens (1996) pero con un foco en las identidades colectivas asociadas a las barras más que en una referencia a la nacionalidad.
A diferencia de otros deportes masivos, el rodeo no se sostiene en la maquinaria cultural provista por los medios de comunicación ni participa de contiendas internacionales, lo que lo hace especialmente atractivo para su estudio: más allá de los alardes de las autoridades, su práctica se ejerce con relativa autonomía a través de las distintas federaciones, asociaciones y clubes que se extienden por todo el territorio del país. Aunque el Comité Olímpico de Chile reconoce a la Federación del Rodeo Chileno como la organización representativa oficial, también existe la Federación Nacional de Rodeos y Clubes de Huasos de Chile, creada en $1986 .{ }^{4}$ Frente al rodeo oficial o patronal - como lo llamaré aquí, esta asociación creó el rodeo laboral, estableciéndose una correspondencia entre los valores cultivados en la medialuna y su expresión de clase, toda vez que en torno al primero se agrupan los más conspicuos representantes de las elites dominantes. En las otras federaciones y clubes encuentran lugar las clases menos acomodadas e, incluso, en las periferias empobrecidas, como veré más adelante, se proyectan algunos de sus reflejos.

El rodeo comparte con otros deportes la autonomización del impulso agonal que se asocia al elemento espectacular, masivo y profesional, lo que lo separa del juego en tanto expresión del espíritu predominantemente recreativo (Huizinga 2005; Recasens 1996). El rodeo es como el fútbol en Argentina, en palabras de Archetti (1999), una arena para el "macho nacional", arena en la que las tendencias organizadoras de la sociedad

\footnotetext{
Ver: Federación de Rodeo (https://ferochi.cl/) y Federación Nacional de Rodeos y Clubes de Huasos de Chile (http://fenaro. $\mathrm{cl} /$ ). Debe hacerse presente que el Reglamento de Rodeo establece distintas categorías según sea la capacidad de convocatoria que el deporte tenga para garantizar el desarrollo de las distintas competencias que incluye (Federación del Rodeo Chileno 1970)
} 
se hacen presente. El modelo de "macho nacional" en la fiesta chilena se construye de manera peculiar, estableciéndose un conjunto de complicidades que, según argumento aquí, permite coptar y poner al servicio de la dominación los espacios de resistencia que eventualmente pudiesen poner en riesgo al poder hacendal (Bengoa 1988).

El rodeo no es un deporte internacional $y$, por lo mismo, no cuenta con adversarios provenientes de otros países. ${ }^{5}$ Lo que está en juego en su práctica es la constitución de un orden nacionalista desde dentro, el cual en el pasado forjó competencias entre las haciendas, movilizando lealtades hacia las figuras patronales al interior de cada una de ellas. Se entronca así con una visión conservadora de la que surge "toda una mitología del campo chileno" Bengoa (1990: 92).

El rodeo en tanto despliegue del poder de las elites y asiento de la chilenidad, plantea una compleja dimensión hegemónica que atañe a la relación entre las clases, los géneros y las especies y, por ende, expresa una ontología particular. Esta ontología, entendida como los presupuestos a partir de los que opera cualquier grupo humano en su relación con lo real, se caracteriza por la clara demarcación de los límites entre seres humanos y entre estos y demás especies. Se trata de una construcción naturalista de estas relaciones (Descola 2013) cuya dimensión política resulta conveniente a los intereses de la clase hegemónica. En efecto, el quiebre de los vínculos entre los protagonistas de la fiesta (jinetes, caballos y vacunos) permite la formación de un sustrato

Aún cuando se práctica en la provincia de Cuyo, Argentina (Montory-Gajardo 2016). ritual para la instalación, legitimación y ejercicio del poder. Semejante quiebre se corresponde con los actos de desposesión que hacen posible la dominación.

Asumo, en este sentido, la perspectiva propuesta por Blaser (2013) y Burman (2017) en términos de entender la disputa acerca de la definición de las relaciones entre seres humanos y entre estos y otros-que-humanos como parte de formas contradictorias de constituir lo real. En este campo se enfrentan la ontología relacional subalternizada y la ontología dominante que se alimenta, por una parte, de la disociación del vínculo entre animales y personas, y, al mismo tiempo, de las personas con su trabajo y sus productos.

Esta perspectiva abre la posibilidad de, por la vía de la comparación entre la práctica hegemónica y la popular del rodeo, examinar la relación que se construye entre el ganado y los seres humanos, sus posicionamientos recíprocos y los arreglos normativos que regulan las relaciones entre ellos. Ambas prácticas difieren por el carácter individualizante de una en oposición al carácter colectivo de la otra, no obstante, ambas mantienen un sesgo patriarcal al subordinar a la mujer en su organización.

En términos de sus dimensiones políticas, el rodeo hegemónico se diferencia del popular en que este último genera una suerte de democracia interior que se extiende hacia los animales, mientras que en el primero se instala una jerarquía que separa al animal de sus arrieros y somete a estos a sus deseos. De ello resultan dos modos del ser patriarcal: uno, poliárquico y el otro, plutocrático.

En lo que sigue examino el papel que el rodeo tiene en el Chile contemporáneo. Sostengo 
que su práctica supera con creces el de servir como un mero artificio retórico de la identidad nacional y que, para comprender su papel en el ejercicio de la hegemonía, es necesario examinarlo desde la perspectiva de una economía política informada por las relaciones de género, por las nuevas ontologías y por el análisis ritual.

Para los fines del análisis he tomado como principal referencia las fuentes escritas acerca del rodeo tal cual ha sido practicado en la zona central del país, complementando estas fuentes con observaciones directas, entrevistas y consulta a expertos.

La mirada aquí propuesta permite desmontar las piezas fundantes del rito a través del que las clases hacendales, primero, y las clases políticas, después, legitiman el ejercicio de su poder. Al mismo tiempo, resulta posible promover una comprensión de un fenómeno que ha sido abordado más por su negación que por sus alcances en la sociedad chilena.

\section{El rodeo como expresión del poder hacendal}

En la hacienda el rodeo adquirió su valor simbólico y estratégico (Lago 1999; León Echaiz 1955, 1971; Montory-Gajardo 2016, 2018). No obstante, su práctica se da también en la arriería toda vez que se trata de una faena que permite reunir estacionalmente el ganado en la búsqueda de pasto y de agua. Empero, no cabe duda que la hacienda, en lo que fue su desarrollo histórico hasta la década de 1960 en Chile, concentró la masa ganadera, y encontró en esta actividad un recurso efectivo para convocar a sus trabajadores y, merced de la celebración, consolidar su hegemonía. ${ }^{6}$

La descripción de Claudio Gay (citado por Purcell, 2000: 44) da cuenta de la capacidad que el rodeo tiene de reunir muchedumbres. "Varias centenas de jinetes arrean delante de ellos, los innumerables ganados que entran revueltos en un gran local, rodeados de empalizadas". Y prosigue:

El corral se llena como si un mar viviente se precipitase en el, despues de romper sus diques. El guaso triunfa en medio de esta mezcla furibunda: entonces es cuando se siente rey, y mira con piedad a los habitantes de las ciudades o al viajero europeo que acuden a los rodeos llevados por la curiosidad

El rodeo se suma así a la vendimia y a la trilla como partes del complejo ceremonial de la hacienda que centran en la figura del patrón su eje estructural. "En una hacienda el Patrón es el espejo en que se miran todos; es la primera y más vigorosa personalidad para los inquilinos" se plantea en 1913 desde la Iglesia Católica (Bengoa 1990: 91).

La huella de la hacienda a través de sus rituales es glorificada por la propia elite. "La agricultura, mezcla de actividad productiva y cultura local ... se erige como un baluarte al interior de la construcción de un Chile como símbolo de la nación", señala Claudio Orrego en la presentación del primer tomo del libro Historia del Rodeo Chileno (Montory-Gajardo2016), texto que compila anécdotas, entrevistas, recortes de diarios, y reproducciones de escritos en torno al

6 A modo de ilustración se puede señalar que Bernardo O’Higgins, a objeto de hacer efectiva su herencia, realiza un rodeo un día 29 de enero de 1804, que reúne a todo el ganado de la Hacienda Las Canteras y en 22 días de faena se logran llevar a corral a seiscientos animales (Montory-Gajardo 2016). Es evidente que la masa ganadera constituye prenda de poder, prestigio y riqueza. 
tema. El rodeo se señala en el mismo texto da cuenta de las vicisitudes "de los hombres que formaron esta nación” (2016: 11).

"El rodeo es interesantísimo", sugiere Mario Góngora. "Es una demostración singular de dos manifestaciones típicamente chilenas: el valor viril y, a la vez, una cierta medida, una cierta disciplina y sujeción a las reglas" (2013: 477). ${ }^{7}$ Tal atributo confiere al rodeo su lugar en tanto ícono de una forma de dominación agraria que después se proyecta a las otras esferas del poder y el goberno de la nación. Se distingue en este sentido del rodeo laboral no federado, evento igualmente deportivo pero despojado de los atributos del poder, y del rodeo ganadero referido a continuación.

\section{El rodeo como práctica popular}

En no pocas ocasiones, el historiador Gabriel Salazar ha subrayado la inexistencia del rodeo como una fiesta popular (Fajardo 2017; Olguín 2016). Lo ha hecho en el entendido que el pueblo nunca tuvo animales y que la fiesta lo era de los patrones quienes sí son propietarios. Es incuestionable que el rodeo fue el instrumento de dominación que marcó el desarrollo de la hacienda en Chile y que, para su realización, los inquilinos estaban obligados a prestar sus servicios a estas faenas (Bengoa 1990; Skewes 1998). Pero aventurar la inexistencia de la práctica en el campesinado resulta osado. Los arrieros, hasta el día de hoy, manejan rebaños de animales propios bajo un régimen de trashumancia y, en sus desplazamientos estacionales, el rodeo es una faena colectiva de montaña de carácter

Debo esta referencia a uno de los anónimos revisores de este artículo. enteramente popular que incluye actividades festivas en su realización (Catalán 2015; Razeto 2007). Instrumento y símbolo de la nacionalidad, marcado por un sesgo profundamente clasista y patriarcal, el rodeo, no obstante, es fruto de una tradición popular que merece ser revisitada a fin de relevar la genealogía que permite a la clase dominante apropiarse de un instrumento que le resulta extraordinariamente dúctil para la legitimación de su poder. Mi argumento es que, justamente, la fuerza hegemónica del rodeo patronal deriva de su conexión con y de la transformación de estas prácticas para ponerlas al servicio de la hacienda y el poder.

En su relación con los animales, los arrieros forjan vínculos que dan forma a lo que entiendo como una ontología relacional, esto es, una definición que se deriva de las relaciones entre seres vivos más que de la autonomía entre ellos (Burman 2017). La relación con el mundo animal se instala en el corazón de la definición ontológica que orienta parte de la conducta humana. Los nombres de los individuos y especies, sugiere Levi-Strauss (1992), marcan las distancias entre ellos. Las taxonomías, no obstante, no resuelven los aspectos centrales de aquellos procesos de diferenciación que, en el contexto moderno, procuran resaltar el excepcionalismo humano. Phillipe Descola (2013), Viveiros de Castro (2004) y, particularmente, Eduardo Kohn (2013) han cuestionado la primacía del ser humano, propugnando, en cambio, una comprensión fundada en las relaciones entre especies y las formas como son asumidas en distintos contextos culturales y que es evidenciada, en este caso, por la convivencia entre los arrieros y su ganado.

El rodeo, cuya descripción prefiero referir a un escrito anterior (Skewes 1998) y a los trabajos clásicos que al respecto están disponibles 
(Lago 1999; León Echaiz 1955, 1971), constituye un rito de separación de los animales de su entorno, de los seres humanos de los animales y de los hombres de las mujeres: estas son disociaciones que sirven a la creación de nuevos valores mercantiles cuya realización ocurre en el mercado.

El rodeo arriero plantea una forma alternativa de construir las relaciones entre los seres humanos y los animales. Este se lleva a cabo cuando se reúne el ganado para acarrearle a los valles cordilleranos en los que crece el pasto tras los deshielos (rodeo de entrada), y antes de las lluvias, y traerles al valle (rodeo de salida) durante la temporada invernal (Razeto 2007). El movimiento más importante se produce después de la veranada ya que las vacas vuelven con los terneros nacidos en la montaña y, por lo tanto, es menester reconocer a las crías para integrarles a los rebaños y sus propietarios.

Los rodeos de entrada y salida son actividades de carácter comunitario de las que solo participan los hombres (aunque de modo muy excepcional se nombra a alguna mujer arriera), quienes suben y bajan acompañando a los animales y quedándose junto a ellos o designando arrieros que cumplen con la tarea de cuidarles en los cerros.

Del mismo modo, la tarea de reunir a las vacas solo la pueden cumplir jinetes coordinados para su arreo. El rebaño es llevado a los corrales que en el caso de las montañas de la zona central son hechos con muros de piedra (pircas) (ver figura 1). ${ }^{8}$

En la zona cordillerana del Chile central se mantiene la práctica de construir pircas o muros de piedra que constituyen una tradición prehispánica y que fuera utilizada por los Inka para múltiples propósitos. Esta práctica testimonia, a su vez, una continuidad histórica del poblamiento, marcado por el régimen de la trashumancia (Razeto 2007).
Figura 1. Corral de montaña. Jahuelito.

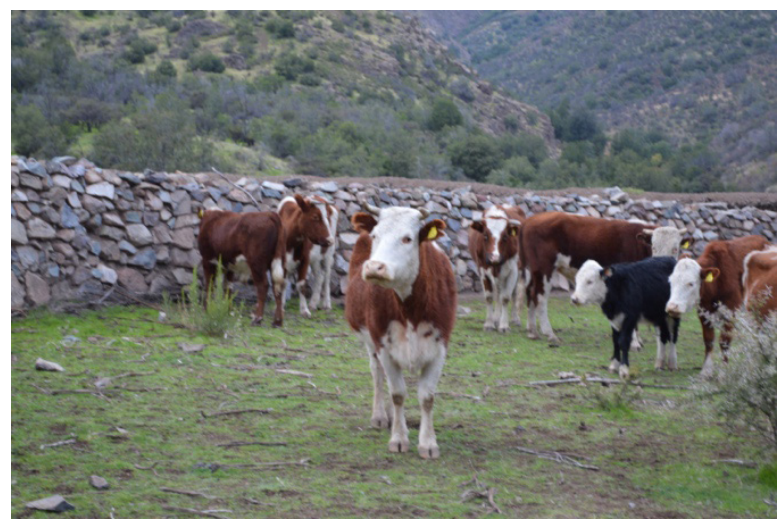

Fuente: Fotografía del autor.

La destreza en el manejo del caballo es objeto de prestigio y no escatiman esfuerzos en demostrarlo los arrieros. Los animales nacidos en la montaña son "lobos", rápidos y escurridizos y desafían a sus captores.

El rodeo es una fiesta en la que se celebra no solo las proezas de cada cual sino que también los encuentros entre parientes y amigos que supone la ocasión. "Los arrieros se conocen entre ellos" y las relaciones creadas a través de la actividad se ven "reflejados en otras esferas relacionales más estrechas como el parentesco y el compadrazgo" (Razeto 2007: 26). El carácter vinculante que se establece en el rodeo encarna y permea toda la vida social, como se expresa en el siguiente testimonio recogido por Catalán (2015: 81) acerca de cómo se crean las amistades.

"Nos conocimos", afirma un arriero, "por intermedio de los animales, porque los íbamos a buscar para allá, y nos encontrábamos, y ahí nos íbamos haciendo amigos. Así que cuando caen los animales de ellos, teníamos que sacárselos para arriba, echárselos para allá nomás. Y ellos 
cuando caía un animal allá igual lo levantaban para acá. Para que no se fueran a los caminos, bajaban a Olmué a las calles. Así que eso, nosotros hemos sido siempre así con la gente de acá y de allá, somos todos amigos. Nos cuidamos unos a los otros, una cosa así.

En estos rodeos no hay figura patronal y el gobierno de la actividad queda en manos del capataz - figura que se corresponde con la reglamentada por la Federación - quien es elegido por el grupo, representando una figura de prestigio y autoridad inter pares.

La práctica del rodeo, desde un punto de vista ontológico, surge en la frontera entre lo salvaje y lo domesticado, ámbito en que las propuestas de Donaldson y Kymlicka (2011), Descola (2013), Viveiros de Castro (2004) y Kohn (2013) adquieren especial relevancia. En el centro de tales propuestas se instala la idea de cohabitación, sea para desensamblar la dicotomía entre lo doméstico y lo salvaje, en el caso del primer autor, sea para comprender las perspectivas recíprocas que definen a unos y otros, en el caso del segundo. Y, en el tercero, para comprender el comportamiento del todo para dar cuenta de sus particularidades. Donaldson y Kymlicka (2013), a su vez, distinguen a los animales que cohabitan con sus contrapartes humanas (co-ciudadanos) de aquellos que transitan entre un mundo y otro (residentes) y de los autónomos que constituyen dominios soberanos.

La invitación de estos autores es la de hacerse cargo de la relación ontológica que se establece entre el ganado, los seres humanos y demás intervinientes del mundo del rodeo; siendo de particular interés analizar los procesos que se desencadenan entre los distintos tipos de posicionamientos recíprocos y discernir los marcos normativos que pudieran conferir derechos y establecer obligaciones entre unos y otros. Es en este marco donde propongo analizar la fisura entre el mundo hacendal y el campesino y las consecuencias ontológicas y estructurales que ello acarrea.

Es en la doble condición del ganado como habitante libre de los cerros y montañas y de rebaño enclaustrado para los fines de su comercialización lo que permite pensar acerca de la forma como a través del rodeo se despliegan distintas modalidades de vinculación. Los animales que escapan al dominio humano y que son difíciles de controlar son las "vacas lobas" (Catalán 2015: 98 y ss.) y lo que las caracteriza es su movilidad, impredecibilidad, independencia en la reproducción y agresividad hacia las personas. Son animales que no se someten y que, a través de su captura, son forzados a transitar hacia el mundo humano.

Los arrieros son figuras transicionales que acompañan a los ganados desde su autonomía montañesa hasta su sometimiento humano $\mathrm{y}$, en ese ejercicio, conviven y aprenden de ellos. El ganado conoce la montaña, los reparos, los árboles junto a los descansos, los cursos de agua y los arrieros atienden a su comportamiento: "Tiene que adaptarse uno a ellas (las vacas) no más" (Catalán 2015: 97). La identidad entre humanos y vacunos en los valles interiores de la montaña refleja su mutuo acomodo a las circunstancias que comparten. La arriería da cuenta de la coordinación entre seres humanos y animales: caballares, perros, humanos, vacas y toros se adecuan recíprocamente para tornar viable la vida de unos y otros.

En el caso de la zona central de Chile, los tres momentos señalados encuentran expresión en la invernada (sometimiento), en la veranada 
(autonomía) y en el rodeo (tránsito entre uno y otro estado). El cambio en el posicionamiento amerita concebirse como parte de un proceso socioambiental, lo que queda expresado en la práctica que se tornó icónica del imaginario nacionalista y que hoy se exhibe como deporte por parte de las clases dominantes. Para fines de lo que sigue es menester distinguir entre el rodeo deportivo y el rodeo de los arrieros, al cual he de referirme en el análisis. Este rodeo se reduce a la actividad colectiva de rodear a los animales para asegurar su traslado entre los sectores altos de la montaña y los llanos. Esta práctica toda vez que está asociada al desplazamiento de animales y humanos y sujeta a un conjunto de actos celebratorios prescritos por la tradición constituye un rito de transición (Van Gennep 1977).

Figura 2. La media luna. Separación de mundos

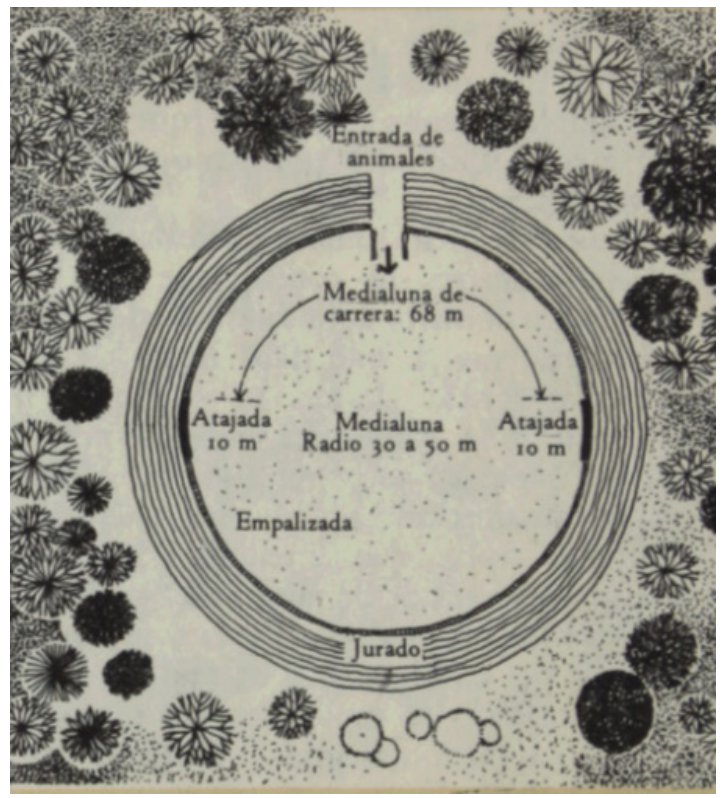

Fuente: León Echaiz 1971.
El rito, según sugiero, tiene la misión de modular las relaciones entre los arrieros y el ganado, de modo de organizar su tránsito ordenado por las convenciones sociales (incluidos los derechos de propiedad), desde la cumbre y hacia el valle. Desde el punto de vista ecológico, el movimiento de animales permite anexar nichos a los disponibles, de modo de ampliar la base productiva que hace posible el sostenimiento de las poblaciones locales. En su movimiento trashumante los animales aprovechan los pastos de montaña, tornándose dependientes de sus propietarios para la obtención del alimento invernal. Paradojalmente, su comercio es lo que solventa su subsistencia como cuando se hace necesario el pago de talaje y no es posible hacerlo sino a condición de vender cabezas de animal para tal efecto.

\section{Transiciones conspicuas, transiciones vitales}

Una forma sucinta de contrastar el rodeo entre arrieros y los de la elite es situar el papel que el rito juega en su práctica. Tal como lo sugiere Van Gennep (1977), los ritos suponen transiciones ontológicas que a través de sus tres fases separación, liminar, agregación - transforman aquello que es su objeto en un ser o ente de cualidad distinta, como es el caso, por ejemplo, de los ritos de iniciación. En el rodeo lo que muta es la condición del ganado en su relación con los seres humanos. A objeto de facilitar la comparación entre uno y otro tipo de rodeo tomaré como referencia las figuras siguientes (Figura 3: El rodeo entre los arrieros y Figura 4: El rodeo oficial). 
Figura 3. El rodeo entre los arrieros

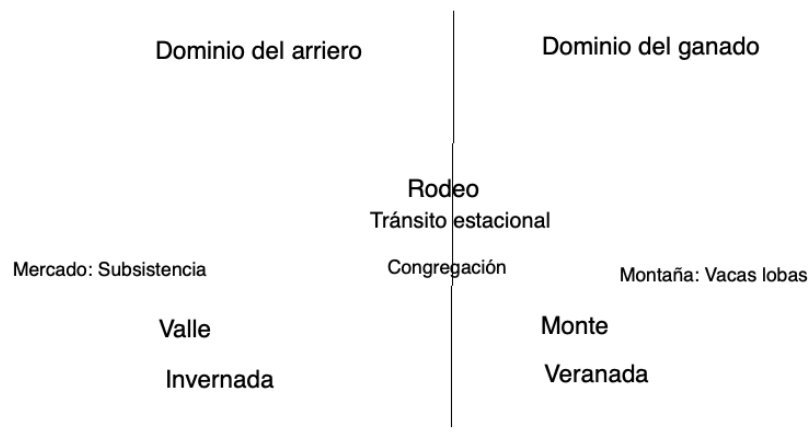

Fuente: Elaboración propia

En la figura 3 se destaca el eje estacional que divide el mundo del arriero. El dominio estival está marcado por el apremio que supone la búsqueda de pastos para los rebaños y por una precaria existencia a través de la que se procura la subsistencia merced, en ocasiones, a la venta de alguna cabeza. La inserción del ganado en el mercado es más bien residual.

A la inversa, la montaña, que se corresponde con la veranada, marca la preeminencia del ganado que pasta libre en las vastas extensiones que se ofrecen a su paso. Como he dicho, el arriero se vuelve dependiente de los animales para encontrar su alimento

El rito en este caso marca la iniciación del ganado en el mundo de los humanos y la de los arrieros en el mundo de los animales; su función principal es producir la integración entre personas y vacunos que se reencuentran. El acto es, pues, congregacional y celebratorio.

La escena del rodeo oficial es muy diferente. la hacienda y el tránsito de los animales tiene

un destino claro: el mercado. En la figura 4 se describen las transiciones involucradas en este deporte:

Figura 4. El rodeo oficial

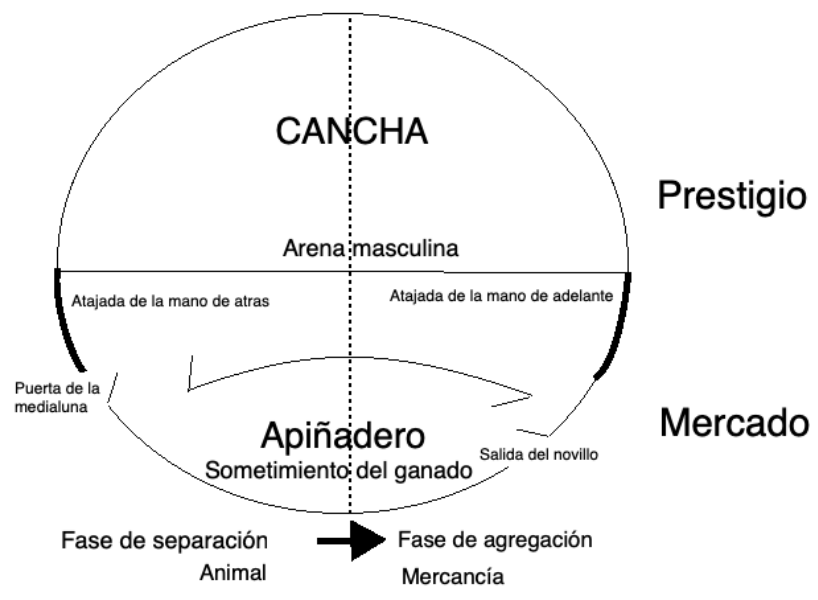

Fuente: Elaboración propia a partir del diseño de una medialuna tipo de acuerdo a la Asociación de Rodeo Chileno Malleco (http:// www.rodeomalleco.cl/medialuna-tipo/)

En esta figura se plantea el tránsito desde la condición animal a la condición de mercancía, redituando su paso prestigio para los cultores del rodeo. La condición primera se marca en el apiñadero donde permanecen los animales reunidos en su condición pre-mercantil y, tras la corrida, emergen individualizados $y$ mercantilizados, incluyendo el control sanitario que se ejerce sobre ellos (Servicio Agrícola Ganadero [SAG] 2018).

Hay dos omisiones conspicuas en estas figuras. Una es la de la mujer. En ambos escenarios del arriero y del rodeo oficial - se prescinde de ella. En el primer caso, la mujer permanece en el valle trabajando tanto en la casa como 
en la faena agrícola. En el segundo se le invita como público a celebrar la proeza masculina exhibida en el ruedo y para acompañar con los preparativos de la fiesta en las ramadas. No obstante, y como sugiero en otro escrito (Skewes 1998), lo que el hombre demuestra (o intenta demostrar) es el control que ejerce sobre los procesos reproductivos que dan vida a los animales y sustento a las personas, dominio que permite, en consecuencia, sujetar a la mujer a la regla patriarcal que prevalece en el rodeo.

La otra invisibilidad es la del acompañante en la collera, a saber, la del trabajador sometido igualmente al dominio patronal Una descripción que se repite a lo largo de las páginas de la Historia del Rodeo Chileno es la de la collera formada por el patrón y algún trabajador de su confianza. A modo de ejemplo:

\footnotetext{
Don José Zapata formaba con su patrón una collera de excepción, conocido en todo Chile, siempre estuvieron en un primer plano nacional, y era conocida la gran admiración de don José por su patrón y su inmensa lealtad en tiempos que fueron muy difíciles en el campo. (Montory-Gajardo 2018: 385)
}

Esta figura resulta clave a la hora de entender la lógica de la dominación que se recrea en el ritual del rodeo. Con el nombre de collera se conoce a la dupla formada por dos jinetes en sus caballos que compiten por las mejores atajadas de los novillos en el rodeo. Visten el atuendo de huaso y establecen entre sí una complicidad que permite no solo someter al ganado, sino que también encantar al público.

Disfrazados de huasos se valen de las destrezas adquiridas desde temprano en la vida y de la fuerza de sus caballos, para arremeter contra los vacunos. Es el poder enmarañado entre animales, seres humanos de clases distintas, donde los más poderosos delegan en los menos las facultades que, paradojalmente, les hacen aún más poderosos. La lealtad de don José, tal como se describe en el relato, es el más importante resorte que de modo indirecto puede aplicarse la regla sobre aquellos a quienes se domina.

\section{El rodeo como espectáculo}

La apropiación de las prácticas populares y de la fuerza de trabajo a ellas asociadas, junto con la regimentación de las relaciones de género y con un posicionamiento ontológico con respecto al mundo animal, en el contexto de una economía de prestigio de gran rentabilidad, son las piezas fundantes de la desigualdad estructural en Chile, tal cual se ritualizan en el rodeo.

El rodeo deportivo hoy ya no es una práctica hacendal. Sin embargo, tal como señalaba en la introducción, se despliega a lo largo del país involucrando a una vasta diversidad de sectores sociales. Si en el pasado el deporte servía para disciplinar a los trabajadores de la hacienda, hoy está mucho más ligado al culto de los valores nacionales y a la celebración de las tradiciones. Y ello ocurre en medios urbanos por la vía de la espectacularización masiva de las contiendas como lo ilustra la que es considerada como la capital del rodeo en Chile: la Medialuna Monumental de Rancagua (ver figura 5).

Es interesante destacar que esta espectacularización del rodeo también se hace presente en sus expresiones de menor envergadura. El foco celebratorio, en estos casos, se centra en los jinetes y en sus trayectorias de vida, pasando sus hazañas a formar parte de la memoria trashumante del grupo. 
Figura 5. La Medialuna Monumental de Rancagua. De la hacienda al mercado.

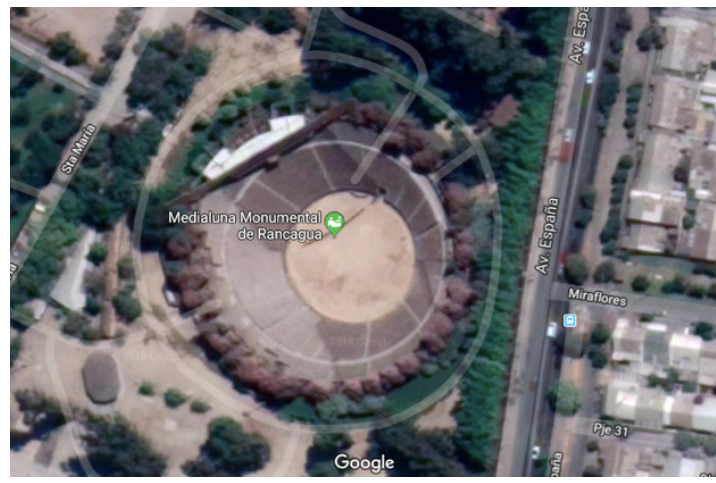

Fuente: Adaptado de Google Earth

En situaciones aún más precarias, el rodeo también aparece espectacularizado, como es el caso de aquellos eventos organizados en las periferias urbano rurales donde más que el atajar ganado lo que se hace es demostrar la destreza ecuestre. Uno de estos eventos ocurre en las riberas del río Cachapoal, donde se ha levantado una medialuna con neumáticos (ver figura 6): "Esta media luna la hicieron hace como cinco años, la hizo el mismo cabro que vive aquí, con sus amigos, hacen amansaduras pa' los dieciocho", se anota (Miranda 2007: 53). A ellas es menester agregar las carreras a la chilena cuya popularidad tiende a incrementarse en las últimas décadas.

"Estas son actividades que hacen los jóvenes del sector, aquí hay un club de huaso y de domadores", señalan los residentes del campamento Ribera Norte (Miranda 2007: 50) y sigue:

Ellos hacen aquí todo su entrenamiento, a veces hacen actividad y domadura aquí para la gente. Todos venimos aquí cuando hacen actividades. Es un club que tienen los muchachos del sector. Entonces ellos de repente traen una cachá de caballos y los doman.
Figura 6. Rodeo popular.

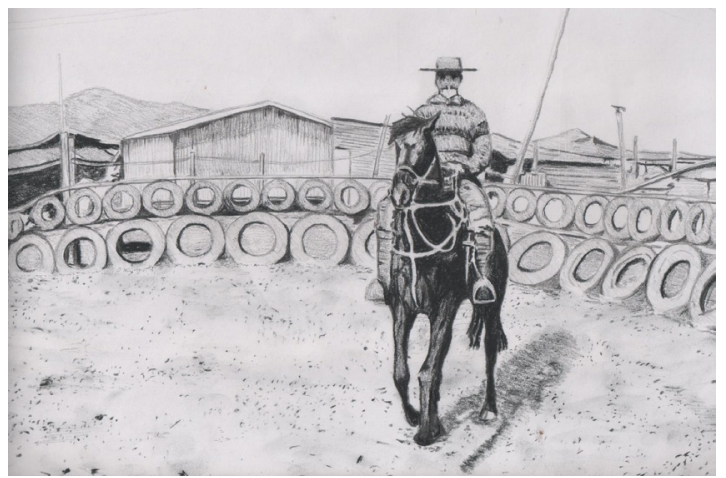

Fuente: Dibujo hecho por Mauricio Cayul a partir de fotografía disponible en Miranda 2007: 53

En la gradiente que va desde la medialuna de Rancagua a la del río Cachapoal hay un sinfín de variaciones y tal vez la única divisoria que pueda trazarse es la que concierne a los procesos de acumulación y de mercantilización, procesos que ocurren en el marco de la generación de excedentes y que se desvanecen a nivel de la sobrevivencia. No obstante, las otras dos contradicciones permanecen inalterables, a saber, la del regimen patriarcal y la del supremacismo humano.

El rodeo plantea el conflicto entre los seres humanos y los animales sobre el control de su poder reproductivo. Habiendo nacido libres, llegado el otoño, los animales deben ser reunidos. Es el momento en que se fragmenta el rebaño, dirimiéndose la propiedad de cada ejemplar, quedando cada individuo debidamente marcado.

La tensión que se pone en juego a través del rodeo es entre la lógica del "criar la vida" y lógica del "recurso natural". La instalación del 
rodeo como parte de la liturgia nacionalista celebrada por las clases hegemónicas supone una fractura ontológica de la comunidad biótica en que se origina la práctica y en la que la mutua dependencia y cohabitación de especies humanas y otras-que-humanas es expropiada para servir intereses que no solo le son ajenos sino que son contrarios a su propia existencia. Tanto el rodeo patronal como el deportivo separan al productor de su producto y al mismo tiempo convierten al animal en mercancía, disociándole de su paisaje y colocándole en un escenario donde su sometimiento se convierte en espectáculo instrumentalizado por quienes alienan de sus capacidades a los arrieros para ponerlas ilusoriamente, en un caso, en manos de un terrateniente disfrazado de huaso, $y$, el otro, al servicio del espectáculo. La triple enajenación la de la mujer y sus capacidades reproductivas, la del productor respecto de sus medios y la del animal en relación a la comunidad, al paisaje y a sus crías - crea fisuras sistémicas que separan la práctica de su medio y a las personas entre sí.

Son múltiples las opresiones que encuentran abrigo bajo el rodeo en tanto liturgia nacionalista. La comunidad imaginada permite el sometimiento de la bestia y el sufrimiento animal, y el rodeo es el testimonio ritual de la nación forjada por sus pro-hombres, según reza la mitología criolla. ${ }^{9}$ A su servicio habrán de ponerse los trabajadores, las mujeres

"Cabe destacar", señala el portal de noticias emol.com, perteneciente a la cadena El Mercurio, "que, en nuestra historia la 'caballería huasa' ha sido decisiva. De hecho, el Cacique Lautaro está considerado como el primer huaso, al deshacer el mito que hombre y caballo eran un todo ... Durante la época de la Independencia, Bernardo O'Higgins Riquelme fue conocido en su manco corralero adiestrado en su fundo las "Canteras" ... El inmortal Santiago Buenas Avaria, conformó su batallón de lanza y machete con sus propios vaqueros y capataces andinos" (Orbe 2008). y la naturaleza. Quedan, en esta escena, fuera de toda consideración moral los vacunos cuya reproducción y muerte sirven al triple propósito de engrandecer la hacienda, incrementar el prestigio y el poder personal y abultar las arcas patronales, al tanto que se engrandece el alma nacional, como lo declara el presidente de la República, al inaugurar una nueva versión del Campeonato Nacional de Rodeo en abril de 2018:

Estoy convencido que el rodeo es un gran abono para esa cultura; esas tradiciones; para nuestra artesanía; para la gastronomía y para tantas lindas tradiciones que ennoblecen el alma de nuestro país y que nacen y se mantiene en el mundo rural. (El Mostrador 2018)

El entusiasmo del Presidente por este abono para la cultura puede tener fundamentos adicionales. El rodeo es abastecido por un negocio que no suele aparecer en los titulares: la crianza de caballos de fina sangre y de caballos corraleros (ver, a modo de ejemplo, http://www1.caballoyrodeo.cl/portal_rodeo/ stat/compraventa/portada.html). Este es un negocio altamente rentable. Se estima que un caballo no cuesta menos de un millón de pesos chilenos y algunos ejemplares han alcanzado precios exorbitantes (el año 2012, un ejemplar fue rematado en 72 millones de pesos, cifra que supera fácilmente los cien mil dólares americanos) (López 2012). Hacia el 2010, los precios de los caballos, entre la VI y X regiones, se pagaban a un precio promedio de $\$$ 2.000.000 (más de tres mil dólares americanos) y sus valores de exportación bordeaban los 60 mil dólares, teniendo como destinos principales Brasil, Uruguay y Argentina (Borgeaud \& Trommer 2010).

Como lo titula un periódico nacional, "un negocio sin rodeos", pero un negocio lo es de 
los grandes criadores y no de los pequeños (Borgeaud \& Trommer 2010). A la vez que ser mercado para caballares, el rodeo lo es para la comercialización del ganado para engorda donde cifras igualmente exorbitantes se transan a partir de estos eventos $y$, aunque más modesta, no es menor la cantidad de dinero que se destina para el arriendo de los novillos. "La misión es tener ganado de calidad para los cinco Clasificatorios y el Nacional. Se seleccionan mil, que pesen entre 380 y 400 kilos y de 18 a 20 meses", dice Adolfo Melo, director de la Federación, quien está a cargo del Fundo El Rodeo en Los Lagos. ${ }^{10}$ Desconozco las cifras totales pero pueden ser estimadas a partir de este dato periodístico: hay 26 mil corraleros en todo el país, y hay " 365 días de actividades cada temporada, enmarcando una cultura propia y una industria millonaria".

Según antecedentes aportados por la Federación de Rodeo, hacia el 2010, en cada temporada se realizaban 440 rodeos, convocando a 5896 jinetes y 9825 socios (Borgeaud \& Trommer 2010). La cantidad de caballos usada era de 40.000 . El rodeo, como concluye la nota periodística antes citada, es una auténtica celebración, aunque Eduardo Tamayo aclare muy serio: "Esto es una competencia, no una celebración. Los que ganan celebran" (Dall'Orso et al. 2018).

La valoración del ganado, refleja la unilateralidad con que se le aborda en una economía de mercado: se hace desde la mirada moderna que separa naturaleza de cultura, en este caso a los animales, sea al precio de su

El toro debe pasar una sola vez en la vida por una medialuna, pues si no, aprenden cómo huir o dónde están las salidas. Luego del torneo, los novillos son vendidos y el nuevo dueño deberá engordarlos pues recién en los 500 kilos van al matadero (Dall'Orso et al. 2018). instrumentalización -motor caballo es la expresión empleada por Prado (1914) - sea al precio de su idealización. El animal aparece como instrumento de prestigio, por una parte, y como mercancía, por la otra.

De especial interés ha sido, en la historia del rodeo, la preocupación por crear y mantener una raza chilena de caballares. Uldaricio Prado (1874-1924), es quien, dentro de la academia, instala esta preocupación. Su argumentación sigue muy de cerca la pureza étnica que hay detrás del ideario nacionalista. Conviene, pues, detenerse en ella:

\footnotetext{
La ascendencia etnográfica de cada una de estas razas caballares, es mui interesante i aun indispensable conocerla, porque ella nos esplicará ... la poderosa influencia que las costumbres de cada nacion han podido tener sobre las caracteres del motor caballo ... de cuyo conjunto morfolójico se deriva cierto tipo característico o sea lo que se ha llamado comunmente una raza caballar. (Prado 1914: 2) ${ }^{11}$
}

"Las razas caballares", arguye Prado (1914: 2), "poseen caracteres étnicos o primitivos que son INHERENTES a cada uno de ellos" (las mayúsculas están en el original). La tarea que el autor se propone, en consecuencia, es recuperar la pureza racial del animal para desarrollarla en todo su potencial:

Para alcanzar entonces el verdadero objetivo práctico que
perseguimos, el aprovechamiento de nuestra población
caballar existente en el sentido de que nos proporcione
el mayor número posible de motores animales útiles,
a los servicios elejidos, por el Mercado consumidor, se
debe comensar por devolverle ... su uniformidad de
constitucion que ha perdido. (p. 628)

Fuera de la escena del poder, en el ejercicio cotidiano del arreo ganadero, el animal más que instrumento es compañero de ruta y en

En esta y siguientes citas del autor se ha conservado la grafía original. 
tanto mercancía solo lo es potencialmente, cuando, como he señalado, los requerimientos del arriero y de su rebaño así lo imponen. ${ }^{12}$ Bajo esta modalidad, humanos y no humanos establecen un vínculo de vida, se tornan co-dependientes $y$, junto con los cursos de agua y pastizales, se hacen parte del entramado vital, constituyendo lo que Rozzi (2012) describe como madriguera. Es en el habitar donde se funda entre humanos y no humanos una ontología relacional. Es allí donde se crean los vínculos orgánicos en que se radican los esquemas morales que propenden a una mejor vida para unos y otros. ${ }^{13}$

El rodeo chileno exhibe la variabilidad de las relaciones que se establecen entre el ganado y los seres humanos -sufrimiento animal incluido. Visto desde la óptica de la ecología política, tales relaciones corresponden al doble posicionamiento sistémico que la ganadería tiene en su contexto histórico: sea en términos del puente que tiende entre distintos ámbitos ecológicos articulados a través del posicionamiento diferencial de los actores en una determinada estructura social, sea de constituir moneda de cambio para transar relaciones de poder y de negocio. En ambos casos, medio de vida o medio de cambio, el ejercicio ritual da curso a la expresión simbólica de las relaciones sociales a las que se somete la actividad.

12 La fortuna del huaso pobre se reduce casi siempre a su caballo, al que cuida con una especie de idolatría, en palabras de Recaredo Santos (citado por Montory-Gajardo 2016: 140).

13 En el contexto de las actuales demandas de los grupos animalistas por la eliminación del rodeo en virtud del maltrato animal, cabe subrayar que las visiones contrapuestas entre defensores del rodeo y defensores de los animales incurren en el mismo error de separar humanos de no-humanos, omitiendo el tipo de relación que entre ellos se construye: para unos es un instrumento financiero y para otros es una mascota antropomorfizada.
Los polos que se identifican son los de la ganadería de subsistencia y la ganadería de ostentación o la espectacularización del manejo de los animales. En un caso, el animal pasa a ser un miembro de una pequeña comunidad moral que sirve de soporte para la mutua protección en la faena en tanto en el otro es un mero instrumento para la escenificación del poder que una clase ejerce sobre la sociedad.

El quiebre se produce cuando la comunidad que constituye el arriero y sus animales pasa a ser el medio de acumulación para otros, quienes acopian en sus corrales los recursos que atestiguan su riqueza y poder. La separación introducida entre persona, animal y paisaje adquiere los ribetes dramáticos de un ritual en el que se exalta simultáneamente el supremacismo patronal, la dominación patriarcal y el del sometimiento tanto de los animales como de los campesinos dependientes, rito cuyo fundamento es el de promover la idea de nación como comunidad, encubriendo a través suyo la divisoria de una sociedad que fuerza a unos a celebrar lo que beneficia a otros.

La lectura de los procesos históricos a partir de expresiones rituales como las que se encarnan en el rodeo permite identificar las distorsiones que introducen en los procesos vitales aquellas conductas que se despliegan a objeto de asegurar privilegios para el goce de las minorías. Estas expresiones rituales dan cuenta de la correspondencia que se produce entre la organización y desigualdad humanas $y$ el distanciamiento y el sometimiento de las especies no humanas. Al mismo tiempo, este análisis da cuenta de la tergiversación del destino de la producción mancomunada de 
humanos y no humanos: el sacrificio que ya no retorna a su fuente sino que se ofrenda al mercado.

\section{Conclusiones}

El rito patronal consagra un posicionamiento ontológico que separa la naturaleza de la cultura, disponiendo el sometimiento de aquella a esta, celebrando la supremacía masculina y de clase en el gobierno de la sociedad. La instalación del rodeo como ejercicio emblemático del país lo legitima como el modelo propio de la condición nacional. El rodeo, a su vez, moviliza una importante cantidad de recursos que, siendo propios de la economía de prestigio, son substantivos en términos monetarios (caballares, aperos, atuendos, instalaciones, además de los costos de inscripción y participación en cada corrida), y que permiten un eslabonamiento hacia abajo a partir de las distintas asociaciones de rodeo y clubes de huasos que canalizan la práctica del deporte. Ello permite que las clases menos pudientes puedan reproducir a su escala el modelo, bajo formato y denominación de rodeo laboral, y generalizarlo hacia los sectores que no participan del Campeonato Nacional de Rodeo, el principal que se celebra en el país.

El ejercicio del poder en la sociedad chilena, tal como aparece ritualizado en la celebración del rodeo, supone un conjunto de complicidades que se articulan a un régimen de clase, patriarcal y supremacista. En tanto deporteespectáculo, el foco del rodeo lo constituye la pareja patronal que valiéndose del sometimiento de los caballares, despliega sus destrezas para doblegar al animal salvaje e incorporarle en forma domesticada a los haberes de la hacienda, en el modelo clásico, o a la reputación asociada al sistema de puntos en la economía del prestigio en el contexto contemporáneo. El espectáculo se ofrece como demostración de fuerza tanto a las mujeres como a los campesinos, y, en ambos casos, la reducción del animal resulta ejemplificadora frente a eventuales expresiones emancipadoras. La fiesta con que culmina el rito, tradicionalmente asociada a las ramadas como dominio femenino, consagra las primacías previstas en su instanciación y permite cooptar la liminalidad que genera el proceso ritual. En la base de esta dramatización se encuentra la imagen del hombre y del hombre poderoso como centro del mundo, imagen en la que se plasma la ontología moderna que se nutre de la disolución de vínculos para el beneficio de las clases hegemónicas.

A este ejercicio de poder se opone la convivencia que los arrieros establecen con los animales y entre sí como comunidad de pares masculinos. En este escenario cobra primacía la voluntad colectiva fundada en el bienestar común y solventada por la experiencia y los talentos individuales que son objeto de reconocimiento colectivo. La complementariedad y reciprocidad en la realización de las tareas, la protección del ganado y la atribución de derechos y deberes sobre la base de la participación efectiva en la tarea común confieren al rodeo un valor congregacional que se refleja en la ontología relacional como el modelo interpretativo que los actores usan en la construcción de su mundo. No obsta ello que, en este marco, persista un modelo patriarcal que rige las relaciones de género y que en su ejercicio propicie la admiración hacia quienes detentan las más altas posiciones de poder en la sociedad.

Entre arrieros y hacendados, figuras de carácter más bien emblemáticas, se interponen 
procesos modernizadores a través de los que la institución del rodeo se reformula, desdoblándose y complejizándose al mismo ritmo en que se multiplican las relaciones en la sociedad contemporánea. El rodeo, no obstante, se mantiene como uno de los rituales a través de los que se sacralizan las relaciones de dominación en los distintos niveles en que opera. Si se me permite el uso de la analogía, en el rodeo se encuentra el átomo del poder que, al modo levistrosiano, permite eslabonar sistemas cuyas partes y relaciones se multiplican. La complicidad masculina entre el patrón y su collera facilita, en escenarios cambiantes, integrar la desigualdad para constituirla en fuente de aceptación colectiva y, por lo tanto, fundar su legitimidad.

En el escenario actual, con el ascenso de los movimientos nacionalistas a nivel global, el rodeo pareciera no solo ser impermeable frente a las críticas de los movimientos animalistas y de grupos que promueven la igualdad de género y de clase sino que, además, su popularidad tiende a incrementarse. Así, al menos lo proclaman las asociaciones de rodeo y la prensa. No obstante ello, los intelectuales antes citados anuncian el fin de la actividad. Tal contradicción es sintomática de la distancia entre la academia y los escenarios de la vida cotidiana en el mundo popular. La crítica transformada en negación no pareciera tener un efecto distinto que el de exacerbar el culto nacionalista que este y otros deportes puedan instigar. El análisis precedente invita, en este sentido, a la promoción de valores que, tomando como referencia las prácticas de los arrieros, tiendan a democratizar los espacios de su realización, a equilibrar las relaciones de género y a dar protección a los animales.

\section{Bibliografía}

Alabarces. (2006). Fútbol y patria: el fútbol y (la invención de) las narrativas nacionales en la Argentina del siglo XX. Papeles Del CEIC, (25), 1-18.

Alabarces, P. (1998). Lo que el estado no da, el fútbol no lo presta: los discursos nacionalistas deportivos en contextos de exclusión social. Presented at the Latin America Studies Association, Chicago, II. Retrieved from http://lasa.international. pitt.edu/LASA98/Alabarces.pdf

Alabarces, P. (2015). Deporte y sociedad en América Latina: Un campo reciente, una agenda en construcción. Anales de Antropología, 49(1), 11-28.

Archetti, E. P. (1999). Masculinities: football, polo, and the tango in Argentina. Oxford, UK ; New York: Berg.

Bauer, A. (1994). La sociedad rural chilena (P. Matta, Trans.). Santiago de Chile: Andrés Bello.

Bengoa, J. (1988). Historia social de la agricultura chilena. Tomo II: El poder y la subordinación. Santiago: Ediciones Sur.

Bengoa, J. (1990). Historia Social de la Agicultura Chilena. Tomo II: Hacienda y Campesinos. Santiago [Chile]: Ediciones Sur. Retrieved from http://www.estudiosindigenas.cl/trabajados/ haciendas_campesinos.pdf
Blaser, M. (2013). Ontological Conflicts and the Stories of Peoples in Spite of Europe: Toward a Conversation on Political Ontology. Current Anthropology, 54(5), 547-568. https://doi. org $/ 10.1086 / 672270$

Borgeaud, M., \& Trommer, P. (2010). Análisis económico financiero de los criaderos de caballos criollos chilenos. ¿Pasión o negocio? (Tesina presentada como requisito para optar al Grado de Licenciado en Administración). Universidad Austral de Chile, Valdivia, Chile.

Burman, A. (2017). La ontología política del vivir bien. In K. de Munter, J. Michaux, \& G. Pauwels (Eds.), Ecología y reciprocidad. (Con)vivir Bien, desde contextos andinos (pp. 155-173). La Paz, Bolivia: Cepa/Plural/Tari.

Catalán, E. (2015). Relaciones humano-ambiente en el Parque Nacional La Campana: Una trayectoria de encuentros y desencuentros entre Comunidades Locales y el Área Protegida (Memoria para optar al título profesional de Antropóloga Social). Universidad de Chile, Santiago.

Dall'Orso, C., Hermosilla, D., \& Amenábar, P. (2018, abril 7). Un negocio sin rodeos. La Tercera. Recuperado a partir de http://www. latercera.com/el-deportivo/noticia/negocio-sin-rodeos/125662/ 
Da Matta, R., Neves, L., Lahud, S., \& Vogel, A. (1982). Universo do Futebol. Esporte e sociedade brasileira. Rio de Janeiro: Pinakotekhe. Retrieved from https://ia800602.us.archive.org/0/ items/UniversoDoFutebolRobertoDaMatta/Universo\%20do\%20 Futebol\%20-\%20Roberto\%20DaMatta.pdf

Descola, P. (2013). Beyond nature and culture. (J. Lloyd, Trans.). Chicago: University of Chicago Press.

Donaldson, S., \& Kymlicka, W. (2011). Zoopolis: a political theory of animal rights. Oxford; New York: Oxford University Press.

El Desconcierto. (2018, April 9). "Es parte de nuestra riqueza": Piñera asiste a campeonato de rodeo y sale en defensa de la actividad. Retrieved December 15, 2018, from http://www. eldesconcierto.cl/2018/04/09/es-parte-de-nuestra-riquezapinera-asiste-a-campeonato-de-rodeo-y-sale-en-defensa-de-laactividad/

El Mostrador. (2018, abril 9). La férrea defensa de Sebastián Piñera al rodeo como deporte nacional. Recuperado a partir de http://www.elmostrador.cl/noticias/multimedia/2018/04/09/videola-ferrea-defensa-de-sebastian-pinera-al-rodeo-como-deportenacional/

Fajardo, M. (2017, August 29). Historiadores ponen la lápida al rodeo: ya no responde a la cultura del Chile del presente aseguran. Retrieved January 5, 2019, from https://www.elmostrador.cl/ cultura/2017/08/29/historiadores-ponen-la-lapida-del-rodeo-yano-responde-a-la-cultura-del-chile-del-presente/

Federación del Rodeo Chileno. (1970). Estatutos y reglamentos generales de corridas de vaca y de movimientos de rienda. Santiago: FdelRCh. UC,

Góngora, M. (2013). Diario, Santiago: Universitaria-Ediciones

Huizinga, J. (2005). Homo ludens: el juego y la cultura. (E. Imaz, Trans.). México: Fondo de Cultura Económica.

Kay, C. (1980). El sistema señorial europeo y la hacienda latinoamericana. México D.F.: Editorial Era.

Kohn, E. (2013). How forests think: toward an anthropology beyond the human. Berkeley : University of California Press.

Lago, T. (1999). El huaso. Chile: Sudamericana.

León Echaiz, R. (1955). Interpretación histórica del huaso chileno. Santiago [Chile]: Universitaria.

León Echaiz, R. (1971). Diversiones y juegos típicos chilenos. Santiago [Chile]: Quimantú.

Lévi-Strauss, C. (1992). El pensamiento salvaje (F. GonzálezAramburo, Trans.). México: Fondo de Cultura Económica.

López, M. J. (2012, noviembre 22). Negocio al galope. Qué Pasa. Recuperado a partir de http://www.quepasa.cl/articulo/ negocios/2012/11/16-10597-9-negocio-al-galope.shtml/

Miranda, H. (2007). Al margen. La vida cotidiana en los bordes del río Cachapoal. Registro etnográfico, fotográfico y pictórico. Rancagua, Chile: Primeros Pasos Ediciones.

Montory-Gajardo, A. (2016). Historia del rodeo chileno. Tomo I. Santiago de Chile: Federación del Rodeo Chileno, Gobierno Regional Metropolitano.

Montory-Gajardo, A. (2018). Historia del rodeo chileno. Tomo II. Santiago de Chile: Federación del Rodeo Chileno, Gobierno Regional Metropolitano.

Muller, J. (2004). La profesionalización del rodeo en Chile (1960-1980). (Tesis de Grado para optar a la Licenciatura en Historia). Pontificia Universidad Católica de Chile, Santiago.

Olguín, C. (2016, September 13). Gabriel Salazar y ex líderes estudiantiles: "Se creen la muerte y siguen el camino de la clase política para ser diputaditos" | El Dínamo. Retrieved January 5, 2019, from https://www.eldinamo.cl/nacional/2016/09/13/gabrielsalazar-historiador-movimiento-estudiantil/

Orbe. (2008, enero 10). Un 10 de enero de 1962 el Rodeo fue declarado deporte nacional Fuente: Emol.com. Recuperado a partir de http://www.emol.com/noticias/nacional/2008/01/10/288163/ un-10-de-enero-de-1962-el-rodeo-fue-declarado-deportenacional.html •

Prado P., U. (1914).El caballo chileno 1541 a 1914: es udio zootécnico e histórico hípico. Santiago: Imprenta Santiago. Disponible en http://www.libros.uchile.cl/737

Purcell, F. (2000) Diversiones y juegos populares: formas de sociabilidad y crítica social, Colchagua, 1850-1880. Santiago de Chile: Dirección de Bibliotecas, Archivos y Museos, LOM Ediciones; Centro de Investigaciones Diego Barros Arana.

Razeto, J. (2007). Hacia una gestión comunitaria y sustentable de ecosistemas de montaña en el valle del Aconcagua. In Jorge Razeto, D. Pavlovic, A. Cornejo, C. Bustos, A. Madrid, J. Cerda, \& R. Osorio (Eds.), Estudios de la Vida en las montañas de Aconcagua (pp. 9-46). San Felipe, Chile: CIEM Aconcagua.

Recasens, A. (1996). Las barras bravas: estudio antropológico. Santiago [Chile]: Bravo y Allende.

Rozzi R. (2012). Biocultural ethics: the vital links between the inhabitants, their habits and regional habitats. Environmental Ethics (34), 27-50.

SAG. (2018). Identificación animal oficial [Sitio web oficial]. Retrieved May 3, 2018, from http://www.sag.gob.cl/ambitos-deaccion/identificacion-animal-oficial

Skewes, J. C. (1998). El rodeo, una metáfora del tiempo viejo. Revista Austral de Ciencias Sociales, (2), 69-80.

Van Gennep, A. (1977). The rites of passage (Repr. d. Ausg. 1965). London: Routledge and Kegan Paul.

Viveiros de Castro, E. (2004). The Transformation of Objects into Subjects in Amerindian Ontologies. Common Knowledge, 10(3), 463-484. 